Printed in Great Britain

\title{
Isodensity Ultracentrifugation of Foot-and-Mouth Disease Virus in Caesium Chloride*
}

\author{
By R. TRAUTMAN AND S. S. BREESE, JUn. \\ Plum Island Animal Disease Laboratory, Animal Disease and Parasite Research \\ Division, Agricultural Research Service, United States Department of Agriculture, \\ Greenport, Long Island, New York, U.S.A.
}

(Received 23 May 1961)

\begin{abstract}
SUMMARY
A rapid centrifugation method for purifying foot-and-mouth disease virus (FMDV) combined an isodensity separation below a moving zone separation in the same tube. Two ml. of crude infectious fluid were introduced over a $3 \mathrm{ml}$. nonlinear $\mathrm{CsCl}$ gradient in a swinging bucket rotor. This preformed gradient provided a gradual increase from density 1.0 to $1.3 \mathrm{~g} . / \mathrm{ml}$. and a step from 1.3 to $1 \cdot 6 \mathrm{~g} . / \mathrm{ml}$. After centrifugation for $4 \mathrm{hr}$. at 37,000 rev./min. $(120,000 \mathrm{~g})$ and $4^{\circ}$, a $1 \mathrm{~mm}$. wide light scattering zone was observed with type A virus near the bottom, clearly separated below debris extending from density $1 \cdot 3$ to the meniscus. The narrow light scattering zone contained ( $40 \pm 12 \%$ ) of the FMDV infectivity and its $\mathrm{CsCl}$ isodensity was $1.43 \pm 0.01 \mathrm{~g} . / \mathrm{ml}$. Southern bean mosaic virus and bacteriophage $\phi \mathrm{X} 174$ behaved similarly and were useful as density markers. Virus suspensions concentrated an average of 8 fold retained $(47 \pm 16) \%$ of their infectious units and were studied in the analytical ultracentrifuge directly. Dialysed concentrated virus revealed characteristic particles in an electron microscope. Exposure to concentrated impure $\mathrm{CsCl}$ decreases the stability of the infectivity to such an extent that in $40 \% \mathrm{CsCl}$ its half-life is about 4 days.
\end{abstract}

\section{INTRODUCTION}

A rapid method was sought for concentrating and purifying the virus of foot-andmouth disease (FMDV). Since this small virus (about $23 \mathrm{~m} \mu$ diameter) is harvested at low concentration in the presence of large amounts of tissue debris, purification by differential centrifugation alone is very difficult. In addition to the time required, the repeated formation and resuspension of pellets leads to prohibitive losses of particles and infectivity. Meselson, Stahl \& Vinograd (1957) demonstrated the efficacy of isodensity centrifugation in concentrated $\mathrm{CsCl}$ solutions for dense biological macromolecules, emphasizing that the field could be used to make the gradient. Previously, 'isopycnic' (Anderson, 1955) centrifugation had been used primarily for lipoproteins (reviewed by Lindgren \& Nichols, 1960) and low density cellular components (reviewed by deDuve, Berthet \& Beaufay, 1959). The use of a pre-

* Presented at Fifth Annual Meeting of the Biophysical Society, St Louis, Missouri, U.S.A. February 1961. 
formed gradient takes advantage of the fact that very large particles form bands before the $\mathrm{CsCl}$ or sucrose used for the density gradient reach equilibrium. Applications of isodensity methods using either 'field formed' or preformed gradients have been extensively reported for nucleic acids and viruses ('Spinco' Technical Reviews, 1960; Matthews, 1959; Brakke, 1961).

Recently, Matthews (1960) used a preformed linear gradient from 1.26 to $1 \cdot 46 \mathrm{~g}$./ ml. with a small volume of turnip yellow mosaic virus layered on top. Centrifugation was only for $4 \mathrm{hr}$. at $\mathbf{3 2 , 0 0 0} \mathrm{rev} . / \mathrm{min}$. at low temperature. Light scattering fractions were dialysed to remove $\mathrm{CsCl}$ for further studies. He used both bucket and angle rotors. The non-linear preformed gradient method described here is a modification which uses a very low density near the top of the tube to permit a velocity separation followed by the formation of a band in the steep isodensity region below.

The use of moving zone techniques in a slight density gradient of sucrose or $\mathrm{D}_{2} \mathrm{O}$ have been previously reported for FMDV (Strohmaier \& Mussgay, 1959; Trautman, Savan \& Breese, 1959; Breese, Trautman \& Bachrach, 1960). Fortunately, the infectivity of the FMDV is not lost so quickly in the high $\mathrm{CsCl}$ concentration as to preclude measurement of its isodensity value. Once this was determined, various ways of utilizing isodensity methods in combination with other techniques became possible.

\section{METHODS}

Virus source. FMDV, type A, strain 119 suspensions were used as collected from infected cultures of bovine kidney epithelial cells or after partial purification by methanol precipitation (Bachrach \& Breese, 1958). They were titrated in 4 oz. prescription bottles by the plaque assay method (Bachrach, Callis, Hess \& Patty, 1957). Vesicular fluid removed from the hind pads of guinea-pigs $24 \mathrm{hr}$. after inoculation with FMDV type A, strain GB was another source of virus. This virus had been highly adapted to guinea-pigs before receipt by this laboratory. It was titrated in suckling mice (Skinner, Henderson \& Brooksby, 1952; Graves \& Poppensiek, 1960) at decimal dilutions, with 10 mice per dilution. End-points were computed by the moving average method (Thompson, 1947) with a span of three. The assay error was in the order of $100 \%$ for one standard deviation, which was somewhat greater than that of the plaque assay. In some experiments, starting materials were clarified by shaking with an equal volume of chloroform in the cold, centrifuging at low speed, and recovering the aqueous phase (Pyl, 1953; Bachrach \& Breese, 1958). The southern bean mosaic virus (SBMV) was kindly supplied by Dr T. E. Cartwright, University of Pittsburgh, Pennsylvania, and the bacteriophage $\phi$ X 174 by Dr R. L. Sinsheimer, California Institute of Technology, Pasadena, California.

Solutions. 'Purified' $\mathrm{CsCl}$ was used as obtained from Fisher Scientific Co. (Fairlawn, New Jersey). The pH values of solutions were measured before use and adjusted to $\mathrm{pH} 7 \cdot 4-7 \cdot 8$, usually with acid. The buffer used in the centrifugation was 0.5 M-tris (2-amino-2-hydroxy methyl propane-1:3-diol) adjusted to $\mathrm{pH} \mathbf{7 \cdot 2 - 7 \cdot 6}$ with $\mathrm{HCl}$.

Density measurement. The method of Jacobsen \& Linderstrøm-Lang (1940) was used, with bromobenzene as the lower and a mixture of $m$-xylene and bromobenzene as the upper immiscible fluid. Even with water saturated columns, the slow drift of 
drops to higher densities was observed as reported by Miller \& Gasek (1960). Readings were taken within $2 \mathrm{~min}$. and calibrating drops were always used. Measurements were converted to $d_{4}^{20}$, the weight (g.) of $1 \mathrm{ml}$. of solution at $20^{\circ}$.

Preparative ultracentrifugation. A Spinco (Beckman Instruments, Spinco Division, Palo Alto, California) swinging bucket rotor SW-39 with cavity extending from 5.5 to $10.0 \mathrm{~cm}$. was used in the Models $\mathrm{E}$ and $\mathrm{L}$ ultracentrifuges operated between 30,000 and $37,000 \mathrm{rev} . / \mathrm{min}$. at $4-15^{\circ}$, with most runs below $10^{\circ}$. In some preliminary equilibrium experiments, tube adaptors allowed the use of $2 \mathrm{ml}$. quartz or $0.8 \mathrm{ml}$. lusteroid tubes. The experiments started with the tube contents uniformly
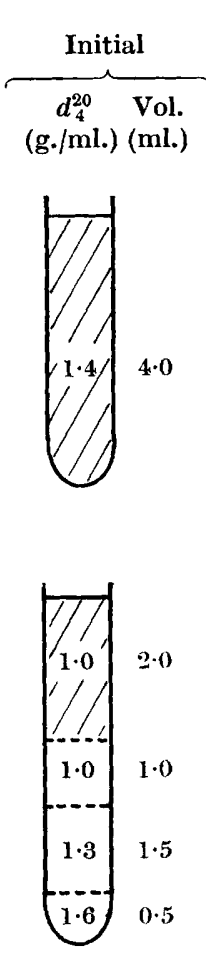
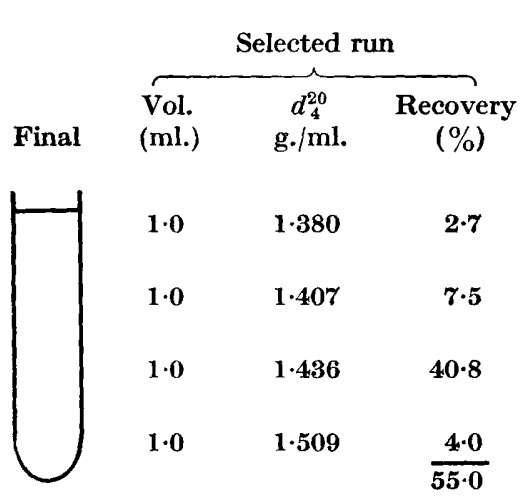

$\begin{array}{rr}1.0 & 1.380 \\ 1 \cdot 0 & 1.407 \\ 1 \cdot 0 & 1.436 \\ 1.0 & 1.509\end{array}$

$\mathbf{A}$

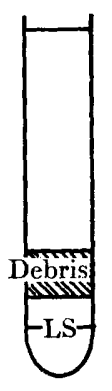

$$
\mathbf{2} \cdot \boldsymbol{7}
$$$$
7 \cdot 5
$$

$\frac{4 \cdot 0}{55 \cdot 0}$

$3 \cdot 6<1 \cdot 1$

$1 \cdot 7$
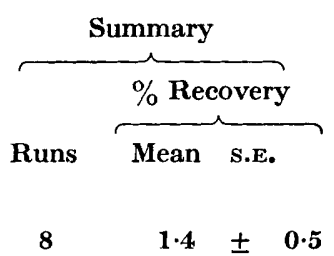

8

$$
\begin{array}{r}
1.4 \pm 0.5 \\
15.0 \pm 7.0 \\
19.0 \pm 9.0 \\
\frac{2.0}{37.4} \pm 1.0
\end{array}
$$

$40 \cdot 8 \quad 9$

8

13

$0.3 \pm 0.3$

$\begin{array}{rrrrr}0.40 & 1.341 & 0.4 & 23 & 5.5 \\ 0.55 & 1.417 & 88.5 & 25 & 40.0 \pm 3.0 \\ 0.47 & 1.516 & \frac{12 \cdot 1}{102.7} & 24 & \frac{6.0}{51.8}\end{array}$

B

Fig. 1. Isodensity preparative ultracentrifugation of FMDV, type $A$ by two methods : (A) field formed gradient; (B) non-linear preformed gradient. Initial-densities and volumes in SW 39 tubes before centrifugation; shaded regions indicate infectious fluid. Final-appearance of tubes and volumes of fractions collected in selected runs after centrifugation; LS is light scattering zone. Selected run-density and \% recovery of infectivity in each fraction: (A) $18 \mathrm{hr} ., 30,000 \mathrm{rev} . / \mathrm{min} ., 15^{\circ}$. (B) $4 \mathrm{hr} ., 37,000 \mathrm{rev} . /$ min, $6^{\circ}$. Summary-mean and standard error of the mean of the log percentage recovery averaged over the number of runs indicated.

distributed, having been adjusted to about $1.40 \mathrm{~g} . / \mathrm{ml}$. density with $\mathrm{CsCl}$. The nonlinear isodensity experiments started with $2 \mathrm{ml}$. of infectious fluid layered over $3 \mathrm{ml}$. of a preformed gradient of $\mathrm{CsCl}$ as shown at the left in Fig. 1B. This initial gradient was made in the cold by layering first $0.5 \mathrm{ml}$. of $50 \%(\mathrm{w} / \mathrm{w}$ ) $\mathrm{CsCl}$ having 
a density of $1.6 \mathrm{~g} . / \mathrm{ml}$., then $1.5 \mathrm{ml}$. of $30 \%(\mathrm{w} / \mathrm{w}) \operatorname{CsCl}(\mathrm{a} 1: 1, \mathrm{v} / \mathrm{v}$, dilution of the $50 \%(\mathrm{w} / \mathrm{w})$ stock $\mathrm{CsCl})$, and finally $1 \mathrm{ml}$. of buffer. The upper of these two boundaries was stirred by twirling a wire bent in a saw-tooth pattern to give a smooth gradient from 1.0 to $1.3 \mathrm{~g} . / \mathrm{ml}$., whereas the lower boundary was left as a step from 1.3 to $1.6 \mathrm{~g} . / \mathrm{ml}$., but it did not remain discontinuous because of diffusion and redistribution in the centrifugal field. In some experiments the volume of the starting sample was increased, which necessitated a decrease in the volumes of the upper two solvent layers forming the moving zone part of the centrifugation. The step from $0.5 \mathrm{ml}$. of the $1.3 \mathrm{~g} . / \mathrm{ml}$. medium to $0.5 \mathrm{ml}$. of the $1.6 \mathrm{~g} . / \mathrm{ml}$. medium was always retained.

After centrifugation, the tubes were removed, placed in a holder at $4^{\circ}$, and inspected by using a pocket flashlight. The light scattering zones could easily be seen in a darkened room looking roughly at right angles to the flashlight beam. Removal of samples was done successively from the top, primarily with a straighttipped Pasteur pipette of $0.5-1.0 \mathrm{~mm}$. bore. When only one fraction was desired, it was obtained by puncturing the tube and withdrawing with a syringe.

Calculations. The percentage recovery $r_{i}$ of each fraction was computed from its volume and infectivity compared with the volume and titre of the starting material. The mean recovery $\bar{r}$ in a series of $n$ replicates was calculated by averaging the $\log$ recovery values. Similarly, the error of the mean was determined from the standard deviation of the $\log$ recovery values $\left(\sigma_{\log r}\right)$ as:

$$
\text { error }=\bar{r}\left[\log ^{-1}\left(\frac{\sigma_{\log r}}{\sqrt{ } n}\right)-1\right] \text {. }
$$

Computation on a log basis was chosen because the assay has a constant percentage error. This, however, gives a lower value for the mean than does averaging on a linear basis.

Optical ultracentrifugation. A 'Spinco' AN-E rotor with a $30 \mathrm{~mm}$. cell was used at 50,740 rev./min. at $4^{\circ}$ in the Model $\mathrm{E}$ ultracentrifuge. The sum of the deflexions of light caused by the concentration gradient set up by $40 \%(w / w) \mathrm{CsCl}$ at equilibrium and the compression gradient was so great under these conditions that three optical modifications were required: the first was to use quartz prisms as cell windows, $-1^{\circ}$ as the lower and $-2^{\circ}$ as the upper; the second was to move the schlieren light source off axis to the rear by about $1 \mathrm{~cm}$., to augment the off-axis effect of the lower wedge window. This result could have been accomplished optically with two $-2^{\circ}$ wedge windows, but would have precluded observation of the pattern early in the run, for which the light source had to be moved closer to the on-axis position. The compensation for the steep solvent gradients was necessary also in the absorption optical system, for which its light source was moved toward the front of the centrifuge. The third modification permitted freedom of movement of the phaseplate schlieren diaphragm across the optical track. This movement was essential to centre the pattern on the photographic plate at angles as low as $10^{\circ}$ (Trautman, 1956).

Electron microscopy. Samples for electron microscopy were dialysed overnight against $0 \cdot 2 \mathrm{M}$ ammonium acetate $(\mathrm{pH} 7 \cdot 6)$. After mixing with a convenient dilution of polystyrene latex particles ( $88 \mathrm{~m} \mu$ diameter) containing bovine plasma albumin, or with $1 \%(\mathrm{w} / \mathrm{v})$ phosphotungstic acid neutralized with $\mathrm{N}-\mathrm{KOH}$ the materials were sprayed from a modified nasal atomizer. Droplets were collected on copper 
grids coated with an evaporated carbon film, shadowed with uranium when required, and examined in an EMU-3B microscope (Radio Corporation of America, Camden, New Jersey).

\section{RESULTS}

Fig. 1 A shows the equilibrium method of isodensity zone centrifugation in which the initial density was adjusted to equal that of the particle of interest. Preliminary experiments were required to determine the proper density before the run illustrated was possible. Since a narrow light scattering zone was not seen with the low titre fluids used, relatively large volume fractions were taken. The density and recovered infectivity of each are given for a typical experiment. The density of the most infectious fraction was $1.436 \mathrm{~g} . / \mathrm{ml}$. Nine such experiments are summarized in the right-hand column and show that the overall recovery was $37 \%$, with most in the third fraction.

Fig. 1B illustrates the preformed non-linear gradient method. In the selected experiment shown, $2 \mathrm{ml}$. of infectious concentrated tissue-culture fluid containing phenol red indicator were layered above the gradient. After centrifugation, the indicator extended from the meniscus through the debris, shown cross-hatched in Fig. 1B, while below this level the solution was transparent except for the narrow light scattering band indicated. The average density in the tube was only $1 \cdot 15 \mathrm{~g} . /$ $\mathrm{ml}$., hence the virus would eventually form a pellet. The fraction containing the light scattering zone was about one-fourth the initial sample volume and contained $89 \%$ of the initial infectious particles. The density gradient was steeper than in the equilibrium case of Fig. $1 \mathrm{~A}$.

Forty such experiments were performed with some differences in the volumes of the initial sample and in the fractions taken. When the initial sample differed from the standard $2 \mathrm{ml}$, the volumes of the 1.0 and $1.3 \mathrm{~g} . / \mathrm{ml}$. layers were adjusted accordingly. Not all fractions were assayed in all experiments, nor were the titrations always successful. The average recoveries of those runs for which there were data are shown in the last column of Fig. $1 \mathrm{~B}$. The light scattering fraction is seen to have contained most of the infectivity with an average recovery of $(40 \pm 12) \%$. In these twenty-five experiments, the volume of this virus fraction varied from $1 \cdot 3$ to 20 -fold. The mean value for 19 runs, which gave a concentration greater or equal to 5 -fold, was $8 \cdot 2$-fold with a recovery of $(47 \pm 16) \%$, showing that the method can be used to concentrate virus solutions. The fractions immediately above and below the light-scattering fraction showed $1 / 7$ of its infectivity. Hence it is reasonable to conclude that the infectivity coincides with the light-scattering material. In thirty-one experiments, in which the entire bottom fraction below the debris was removed, the average recovery was $(75 \pm 25) \%$.

To obtain the best value for the density of the infectious particle, the average was taken of all measurements on the most infectious fraction of the early equilibrium experiments and of those with the preformed gradient. There was a total of eighteen such measurements, giving a mean of $1 \cdot 430 \pm 0.006 \mathrm{~g} / \mathrm{ml}$.

Referring back to the last column of Fig. $1 \mathrm{~B}$, the over-all recovery in the tube was $52 \%$, with $0.3 \%$ in the top $3 \mathrm{ml}$. In order to show that the latter was due to virus which had failed to sediment to the lower portion of the tube, a second centrifugation was performed, using the top fraction as the starting material; in two 
such experiments the recoveries in the lower fraction were 59 and $70 \%$, with 6.2 and $3.7 \%$, respectively, remaining in the top fraction.

Plate 1, figs. 1 and 2, are electron micrographs of the virus fraction after the removal of $\mathrm{CsCl}$. They show characteristic particles both by shadowing and in neutralized phosphotungstic acid (Bradish, Henderson \& Kirkham, 1960). In 14 experiments in which the infectivity before and after dialysis was measured, the average recovery was $(58 \pm 32) \%$ showing that small volumes (e.g. 0.3-1.0 ml.) could be dialysed without difficulty.

During these experiments, the infectivity was measured of 25 samples stored at $4^{\circ}$ for periods ranging from $1 \mathrm{hr}$. to 20 days. The data show roughly that FMDV in $40 \%(\mathrm{w} / \mathrm{w})$ impure $\mathrm{CsCl}$ lost half its infectivity about every 4 days. This is to be compared to a half-life of 4 weeks of crude preparations without $\mathrm{CsCl}$ estimated from the data of Bachrach, Breese, Callis, Hess \& Patty (1957).

The model systems of southern bean mosaic virus (SBMV, $\mathrm{CsCl}$ isodensity about 1.37) and bacteriophage $\phi \mathrm{X}-174(\mathrm{CsCl}$ isodensity about 1.40) were used in developing the preparative procedures (Sinsheimer, 1959). It was found that $50 \mu \mathrm{g}$. gave a readily distinguishable light-scattering zone, and that the gradient which developed in the region of the preformed step could resolve these two markers. A direct experiment in which $50 \mu \mathrm{g}$. of each marker was added to $2 \mathrm{ml}$. vesicular fluid revealed three light-scattering zones with the FMDV about twice as far below the $\phi X-174$ as the SBMV was above it. This indicated that the FMDV light-scattering material was about $1.46 \mathrm{~g} . / \mathrm{ml}$., assuming the above isodensity values for the markers and making no allowance for non-linearity of the gradient. This suggests that the pipetting might have a slight systematic error tending to give too low a value for the density, perhaps by a drainage error. The entire bottom region of this tube was removed and centrifuged to equilibrium in the analytical ultracentrifuge. Plate 1, fig. 3, is a schlieren photograph of this run. Here the $\mathrm{CsCl}$ became redistributed to form the density gradient and the three viruses became separated in layers at their respective isodensity values. It should be noted that the biologically determined isodensity value allows identification of the right-hand large zone as, probably, infectious FMDV. The pattern also shows at about $1.5 \mathrm{~g} . / \mathrm{ml}$. a smaller zone, marked with a question mark, which is specific to FMDV but which is presumably not the whole infectious virus.

\section{DISCUSSION}

The non-linear preformed gradient method described attempts to incorporate the advantages and reduce the disadvantages of the three major types of preparative ultracentrifugation. In particular, complete 'moving boundary' centrifugation (Trautman \& Breese, 1959) concentrates the virus from a large volume into a pellet. It is inefficient, since pellets are difficult to resuspend, and are not depleted in materials of higher sedimentation coefficient than the one desired. Moreover, appreciable purification required many alternating cycles of low and high speed ('differential centrifugation'). The 'moving zone' type ('gradient differential', Anderson, 1955; 'rate zonal', Brakke, 1961) centrifuges virus from an initial zone to one between slower and faster contaminants. It thus does not require repeated cycles nor pellet resuspension. However, the initial zone can only be a fraction of the tube volume and a dilution rather than concentration is obtained in the virus 
fraction. In neither of these two rate methods is there a separation from non-viral substances of similar sedimentation coefficient and, in both types, all the solutes will pack at the bottom, when centrifuged long enough. In contrast, the third type, 'isodensity centrifugation', gives a resolution based on particle density differences and generally can be made to give a concentration into a narrow final zone without a pellet to resuspend. Its two main subtypes depend upon whether the density gradient is preformed or 'field-formed' by the centrifugal redistribution of the small solute molecules of the 'solvent'. The field-formed type ('equilibrium density gradient'; Meselson et al. 1957) generally requires a long time to reach sedimentation equilibrium. The preformed type ('isopycnic gradient', Anderson, 1955; 'equilibrium zonal', Brakke, 1961) can be used for large particles, which will sediment or float to their isodensity positions before the field alters the gradient to its equilibrium value.

Various combinations of the fundamental types have been made either in successive centrifugations or in the same run. The combination used here achieves, in one tube, concentration and separation of the virus from contaminants of slower initial sedimentation coefficient of any particle density as well as separation from those initially faster but of different density. The use of the large step in density obviates any necessity for precise adjustment of initial densities. The 1-3 ml. initial volume is considerably more than the $0.5 \mathrm{ml}$. used in moving zone methods alone. When using 3-4 ml., the process is like the moving boundary method with a porous bottom that allows the virus to penetrate to its density of $1.4 \mathrm{~g} . / \mathrm{ml}$., a density sufficiently greater than that of most of the nonviral contaminants which are thus concentrated above. The moving zone step for this agent, while not essential, should enable greater purity to be achieved in a shorter time than if the virus had to migrate the same distance always in the high density solution. For other systems in which the densities of the virus and the smaller debris are of the same order, the moving zone step would be required.

The increased rate of inactivation of $\mathrm{FMDV}$, due to suspension in $\mathrm{CsCl}$ solution, of about 4 days half-life means that during an equilibrium run of $24 \mathrm{hr}$. $16 \%$ would be inactivated, but in the $4 \mathrm{hr}$. run only $3 \%$ would be inactivated. Since the gradient is preformed, perhaps other salts in combination with $\mathrm{D}_{2} \mathrm{O}$ might be found that would be less harmful. The time of the run has not been extensively studied, but it can be noted that a $4 \mathrm{hr}$. run at $37,000 \mathrm{rev} . / \mathrm{min}$ in a $5 \mathrm{ml}$. SW 39 tube will deposit material of $24 \mathrm{~S}$, which is about one-fourth the sedimentation coefficient of FMDV at $4^{\circ}$ (Breese et al. 1960).

All the experiments in the present work cannot be considered replicates in the sense required for detailed statistical analysis. They represent all runs for which there was either a density or an assay measurement or both. The standard deviation on the $\log$ basis was about $0 \cdot 6$ for the various averages reported whereas the assay error itself is of the order of $0 \cdot 3 \mathrm{log}$.

The excellent technical assistance of $\mathrm{Mr}$ C. E. Bennett in performing the infectivity assays is gratefully acknowledged. 


\section{REFERENCES}

Anderson, N. G. (1955). Studies on isolated cell components. VIII. High resolution gradient differential centrifugation. Exp. Cell Res. 9, 446.

Bachrach, H. L., Breese, S. S., Jun., Callis, J. J., Hess, W. R. \& Patty, R. E. (1957). Inactivation of foot-and-mouth disease virus by $\mathrm{pH}$ and temperature changes and by formaldehyde. Proc. Soc. exp. Biol., N.Y. 95, 147.

Bachrach, H. L., Callis, J. J., Hess, W. R. \& Patty, R. E. (1957). A plaque assay for foot-and-mouth disease virus and kinetics of virus reproduction. Virology, 4, 224 .

Bachrach, H. L. \& Breese, S. S. Jun. (1958). Purification and electron microscopy of foot-and-mouth disease virus. Proc. Soc. exp. Biol., N.Y. 97, 659.

Bradish, C. J., Henderson, W. M. \& Kirkham, J. B. (1960). Concentration and electron microscopy of the characteristic particle of foot-and-mouth disease. J. gen. Microbiol. 22, 379.

BrakKe, M. K. (1961). Density gradient centrifugation and its application to plant viruses. Advanc. Virus Res. 7, 193.

Breese, S. S., Jun., Trautman, R. \& Bachrach, H. L. (1960). Analysis by electron microscopy and infectivity of foot-and-mouth disease virus in moving boundary and zone ultracentrifugation. Arch. Biochem. Biophys. 87, 1.

DeDuve, C., Berthet, J. \& Beaufay, H. (1959). Gradient centrifugation of cell particles: theory and applications. In Progress in Biophysics and Biophysical Chemistry. Ed. J. A. V. Butler \& B. Katz. London: Pergamon Press.

Graves, J. H. \& Poppensiek, G. C. (1960). Determination of the optimum age range of mice for use in experimental studies with foot-and-mouth disease virus. Amer. J.Vet. Res. 21, 694.

JACobsen, C. F. \& Linderstrøm-LANG, K. (1940). Method for rapid determination of specific gravity. Acta physiol. scand. 1, 149.

Lindgren, F. T. \& Nichols, A. V. (1960). Structure and function of human serum lipoproteins. In The Plasma Proteins, vol. n. Ed. F. W. Putnam. New York: Academic Press.

Matthews, R. E. F. (1959). Turnip yellow mosaic virus nucleoprotein particles with differing biological and physical properties. Nature, Lond. 184, 530.

Matthews, R. E. F. (1960). Properties of nucleoprotein fractions isolated from turnip yellow mosaic virus preparations. Virology, 12, 521.

Meselson, M., Stahl, F. W. \& Vinograd, J. (1957). Equilibrium sedimentation of macromolecules in density gradients. Proc. nat. Acad. Sci., Wash. 43, 581.

Mrller, G. L. \& Gasek, J. McG. (1960). Drift of drops in density gradient columns. Anal. Biochem. 1, 78.

PyL, G. (1953). Die Herstellung eines Konzentrat-Adsorbat-Impfstoffes gegen Maulund-Klauenseuche aus gereinigtem Antigen. Arch. exp. Vet. Med. (Leipzig), 7, 238.

Sinsheimer, R. L. (1959). Purification and properties of bacteriophage $\phi$ X-174. J. mol. Biol. 1, 37.

Skinner, H. H., Henderson, W. M. \& Brooksby, J. B. (1952). Use of unweaned white mice in foot-and-mouth disease research. Nature, Lond. 169, 794.

Spinco Technical Reviews (1960). An introduction to density gradient centrifugation. Beckman Instruments, Inc., Spinco Division, Palo Alto, Calif.

Strohmater, K. \& Mussgay, M. (1959). . Bestimmung der Sedimentationskonstante eines infektiösen Prinzips mit Nucleinsäurecharakter aus dem Virus der Maul-und-Klauenseuche mit Hilfe der Gradienten-Zentrifugation. Z. Naturf. 14b, 171.

Thompson, W. R. (1947). Use of moving averages and interpolation to estimate medianeffective dose. Bact. Rev. $11,115$.

Trautman, R. (1956). Operating and comparating procedures facilitating schlieren pattern analysis in analytical ultracentrifugation. J. phys. Chem. 60, 1211.

Trautman, R. \& Breese, S. S., JUn. (1959). Moving boundary theory applied to preparative ultracentrifugation. J. phys. Chem. 63, 1592.

Trautman, R., Savan, M. \& Breese, S. S., Jun. (1959). Partition by zone ultracentrifugation of the two complement-fixing particles in the foot-and-mouth disease virus system. J. Amer. chem. Soc. 81, 4040. 


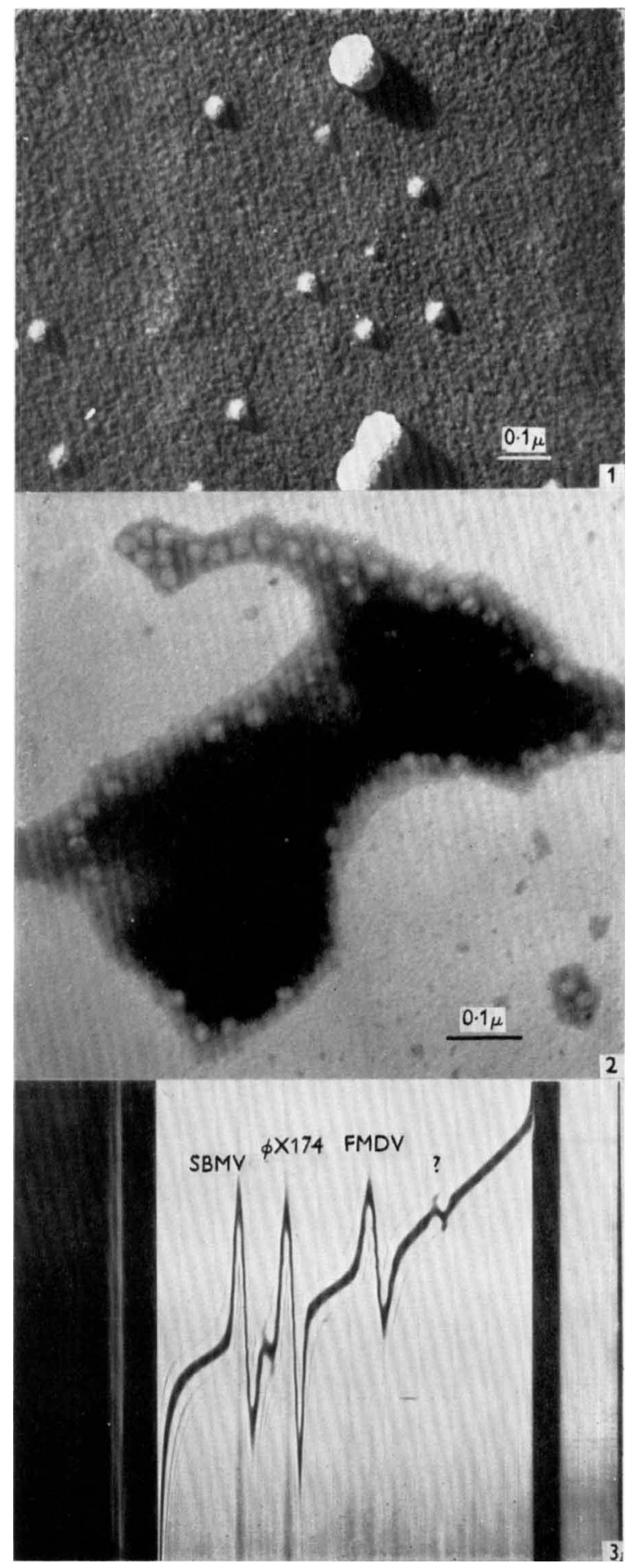

R. TIRAUTMAN AND S. S. BREESE 


\section{EXPLANATION OF PLATE}

Figs. 1, 2. Portions of spray droplets showing FMDV, type A after dialysis of light scattering zone from isodensity ultracentrifugation: Fig. 1, shadowed with uranium, $88 \mathrm{~m} \mu$ polystyrene latex markers. Fig. 2, negative staining with neutralized phosphotungstic acid.

Fig. 3. Isodensity sedimentation equilibrium a mixture of FMDV, type $A$ and other viruses. Schlieren optical pattern after $704 \mathrm{~min}$. at $50,740 \mathrm{rev} . / \mathrm{min}$. at $4^{\circ}$, phaseplate angle $60^{\circ} .1 .0 \mathrm{ml}$. virus fraction from preformed gradient isodensity ultracentrifugation adjusted to $1.9 \mathrm{ml}$. and density $1.423 \mathrm{~g} . / \mathrm{ml}$. Density increases to the right in the direction of the centrifugal field. The question mark is an unidentified zone. 